\title{
Blind Trust in the Care-Giver: Is Paternalism Essential to the Health-Seeking Behavior of Patients in Sub-Saharan Africa?
}

\author{
Ishmael Norman ${ }^{1,2}$ \\ ${ }^{1}$ School of Public Health, (Hoehoe Campus) University of Health and Allied Sciences, Ho, Ghana \\ ${ }^{2}$ Institute for Security, Disaster and Emergency Studies, Accra, Ghana \\ Email: ishmael norman@yahoo.com
}

Received 24 December 2014; accepted 10 February 2015; published 13 February 2015

Copyright @ 2015 by author and Scientific Research Publishing Inc.

This work is licensed under the Creative Commons Attribution International License (CC BY). http://creativecommons.org/licenses/by/4.0/

(c) (7) Open Access

\section{Abstract}

In the past, patients put their lives in the care of doctors in blind trust that the doctors would care for them. This kind of trust is no longer common particularly in the western industrialized nations but the same cannot be said about patients in Ghana and Sub-Sahara Africa. The first concern was whether paternalism was essential in medical practice in Ghana. The second was whether paternalism as an ethical standard should be considered from the ethical lens of the western industrialized nations, rather than from the African cultural context. This entailed a review and examination of the literature on paternalism. We searched databases such as PubMed, Medline and others for reports, editorials and published papers in the English Language. A search on Goggle Scholar on "paternalism in medical practice in Africa" yielded over 380,000 entries and "paternalism in medical practice in Ghana" yielded 2.1 million but more than $99 \%$ were not relevant in each instant. Hand searching of selected printed journals and grey literature such as technical reports, conference proceedings and workshops were also assessed. The studies that met the inclusion criteria were given additional review but those with poor methodology were excluded but discussed in this review. I assigned an overall score and identified the position taken in the publication or report in relation to the objectives and rated them objectively. The papers that received scores above 2.5 out of 4 in the evaluation were further analyzed. I summarized the findings into their respective units, and interpreted them based upon my skills, knowledge and specialization in medico-legal ethics, public health and law. The result shows that not enough research has been done on whether or not paternalism should be encouraged as a regular feature of medical practice in Ghana due to the lack of education. It also shows that paternalism enhances the health seeking behavior of patients despite developments on patient autonomy and capacity. Where the average patient is illiterate in general and in medical matters, the paternalism of the physician may be inevitable. Ethical standards such as Informed Consent, Autonomy, Due Process, Benevolence and No malfeasance should be defined and operationalized in clinical practice within the cultural con- 
text of Sub-Sahara Africa. A systematic indigenization of medico-legal ethical concerns in medical practice is needed in Ghana.

\title{
Keywords
}

\author{
Paternalism, Autonomy, Informed Consent, Physician-Patient Relationship, Ghana
}

\section{Introduction}

"Medical practitioners are beginning to realize that conflict between medical paternalism and patient autonomy would arise if they continue to uphold this dualism as distinct in all circumstances of medical practice." (N. Sivalingam, 2011).

The Nuremburg trials of Nazi doctors for the abuse of human beings used in medical experiments without informed consent after the $2^{\text {nd }}$ World War, led to the development of the Nuremburg Code of medical research. In 1964, the Helsinki Declaration replaced the Nuremburg Code, placing a greater emphasis on ethical tools such as informed consent and autonomy in medical and clinical research. Since then, there have been the systematic enlargements of the protections patients enjoy, sometimes to the abridgement of the autonomy of the physician (Sivalingam, 2011, Braddock et al., 1999). None is advocating that medical ethics in Ghana should go back to the pre-Nuremburg period. Despite years of political atrocities in post-independent Sub-Sahara Africa, there is no engaging narrative on breach of medical ethics by a doctor or a group of doctors in SubSahara.

There have been isolated cases of allegedly poorly designed and executed clinical trials, involving, among others, Pfizer's alleged unauthorized trial of the Trovan drug on about 200 children at a government hospital during a triple epidemic of measles, cholera and meningitis in which 12,000 people died. The episode led to the death of 11 children and various deformities, including deafness, blindness, paralysis and brain damage in 189 others (http://www.nairaland.com/1426056; www.nytimes.com/2011/08/12).

Other charges against a few doctors have been clinical negligence and discriminatory public health interventions, but no major organized medical atrocities have been reported anywhere in Africa as yet. Secondly, it is important to appreciate the fact that it has been argued by other researchers that if the practice of paternalism is not checked, it could diminish the protections offered by Informed Consent in favor of Benevolence and Nonmaleficence as the overriding ethical values (Beauchamp and Childress, 2001; Holland, 2010). The issue here is not which ethical tool is superior. The issue is about pragmatism and clinical realities experienced and repeated daily in health facilities each day across Sub-Sahara Africa.

For example, until quite recently, when it came to the issue of ethical tools, Ghana did not have national legislation on medical ethics delineating the responsibilities of researchers to their subjects. It did not have a national legal framework on medical ethics and other associated but complex issues in healthcare delivery services. In 2012 however, the government of Ghana passed a sweeping Public Health Act, 2012, Act 851. Ghana did not have a national legislation granting specific mandate for the establishment of Institutional Research Review Committees, though the work of these bodies were consistent with general public policy. What existed was a patchwork of policies and rules put together by private but people-centered institutions like the Ghana Health Service, various academic research centers and universities to protect the public from harm that may arise from scientific medical or clinical research.

When it comes to indigenous culture and ethics, the nation has not taken the time to design the parameters for finding solutions to this complex problem, or developing ethical code for the conduct of research specific to the traditional members of the Ghanaian society and their engagement with outside partners (Castellano, 2004). There is therefore the need for the central government and stakeholders in the healthcare delivery system to develop indigenous ethical standards to help improve health care delivery and public health research in general.

\section{Method and Procedure}

The author searched databases such as PubMed, Medline and others for reports, editorials and published papers in the English Language. A search on Goggle Scholar on "paternalism in medical practice in Africa" yielded 
over 380,000 entries and "paternalism in medical practice in Ghana" yielded 2.1 million but more than 99\% were not relevant in each instant. Hand searching of selected printed journals and grey literature such as technical reports, conference proceedings and workshops were also assessed.

For the research question I used search combinations of "Traditional equivalence of informed consent"; or "beneficence or paternalism or autonomy, Ghana only"; "public health legislation with ethics, Ghana, only"; "traditional rules of ethics"; "Ghana medical ethics"; "examples of national work ethics"; "examples of regional medico-legal ethics in national practice".

The inclusion criteria were any report (scholarly paper, opinion, editorial, book chapter, internal post-operations reports, and annual reports) on ethics or investigations on breach of ethics by a health care professional. Medico-legal court cases such as (Elizabeth Vaah v. Lister Hospital, 2010; Emmet v. Eastern Dispensary and Casualty Hospital, 1967; and other papers such as Edwin, AK, 2009; Norman, Aikins, and Binka, 2010; Beauchamp \& Childress, 2001; Buchanan, 2008) were also accessed. If such a case, book or report addressed the thematic areas of this topic such as autonomy, paternalism, choice, capacity or traditional ethics, it was included in the review (Buchanan, 2008; Beauchamp \& Childress, 2001; Norman, Aikins and Binka, 2010; Castellano, 2004).

The author excluded reports that addressed day-to-day clinical and epidemiological operations that were not normally available to the public. Papers that dealt with clinical trials or considered the efficacy of drugs or surgical procedures or technology in general, but which did not address capacity, autonomy, beneficence and paternalism on the national or international level were not included. For example Goodman (2010) dealt with ethics and information technology and the challenges for the clinician-patient relationship.

Rothstein (2010) reviewed the significance of the Hippocratic Oath and its relevance in the modern day health information technology. Gostin and Hodge (1999) drafted a model state public health privacy act and HIPAA (1996) was a major US Public Law on privacy. A "grey literature” was performed non-selectively by reviewing the titles of chapters in major anthologies on ethics in both clinical and public health practice. The reference lists of papers downloaded were searched for related articles for the systematic review.

I found twenty-five publications that met the inclusion criteria. Twenty-four were articles and one was an editorial or opinion as seen in Table 1.

I assigned an overall score and identified the position taken in the publication or report in relation to the objectives. I scored $1=$ entirely relevant; $1 / 2=$ somewhat relevant and $0=$ not relevant at all. I rated them and the papers that received scores above 2.5 out of 4 in this evaluation and were further analyzed. I summarized the findings into their respective units, and interpreted them based upon my skills, knowledge and specialization in medico-legal ethics, public health and law.

\section{Results}

I found twenty-five publications that met the inclusion criteria. Twenty-four were published papers, but one was an editorial or opinion. (Please see Table 1 for the evaluation and assessment of the papers).

\subsection{How the Western Industrialized Nations View Paternalism, Informed Consent and Autonomy}

In the Western industrialized nations such as the United States of America, when the topic of paternalism is discussed, it is often in relation to public health interventions (Buchanan, 2008; Gostin, 2005; Emmanuel and Emmanuel, 1992). Other researchers have argued that central to public health ethics is the question of how to articulate and advance convincing justification why individual liberties should be overridden in the interest of the health of the community (Gillion, 1985).

Paternalism is neither talked about in relation to hospital based clinical practice nor is it spoken about as an enabling means through which health interventions are delivered. Even though it is not difficult to imagine that even in clinical practice in the western industrialized nations for example, paternalism also occurs, perhaps, more frequently than it is assumed, the presumption is that paternalism considerations arise only in discussing encroachment on autonomy in public health (Gillion, 1985).

However, it is inconceivable to think that every single patient in these economies understands autonomy and absolutely knows what is medically good for him without a significant amount of influence from the physician in the patient's decision making ability (Emmanuel and Emmanuel, 1992). Despite these positions of the papers 
Table 1. Critical analysis of papers on paternalism in medical practice in Ghana.

\begin{tabular}{|c|c|c|c|c|c|c|}
\hline Source & $\begin{array}{l}\text { Focused } \\
\text { Question }\end{array}$ & $\begin{array}{l}\text { Literature } \\
\text { Search }\end{array}$ & $\begin{array}{l}\text { Ethical } \\
\text { Argument }\end{array}$ & Conclusion & $\begin{array}{l}\text { Overall } \\
\text { Score }\end{array}$ & Position Taken \\
\hline Edwin, 2009 & 1 & 0 & 1 & 1 & 3.0 & Paternalism is common in medical practice \\
\hline Castellano, 2004 & 1 & 0 & 1 & 1 & 3.0 & $\begin{array}{l}\text { Traditional societies need their own ethical tools } \\
\text { for research and public health }\end{array}$ \\
\hline $\begin{array}{l}\text { Moulton and King, } \\
\text { (2010) }\end{array}$ & 1 & 0 & 1 & 1 & 3.0 & $\begin{array}{l}\text { Informed consent is cardinal to physician-patient } \\
\text { confidentiality }\end{array}$ \\
\hline Francis, (2010) & $1 / 2$ & 0 & 0 & 1 & 1.5 & $\begin{array}{l}\text { Interoperability inherently allows oversight of } \\
\text { patient records }\end{array}$ \\
\hline Rothstein, (2010) & 0 & 0 & 0 & 1 & 1.0 & $\begin{array}{c}\text { Hippocratic Oath is } 2500 \text { years old and perhaps } \\
\text { irrelevant. }\end{array}$ \\
\hline Sivalingam, 2011 & 1 & 0 & 1 & 1 & 3.0 & $\begin{array}{l}\text { Autonomy is family owned in Asian traditional } \\
\text { communities }\end{array}$ \\
\hline Braddock et al., 1999 & $1 / 2$ & 0 & $1 / 2$ & 1 & 2.0 & Patient's autonomy ignores physician rights \\
\hline $\begin{array}{l}\text { Beauchamp \& } \\
\text { Childress, } 2001 \\
\text { Holland, } 2010\end{array}$ & 1 & 0 & 1 & $1 / 2$ & 2.5 & $\begin{array}{l}\text { Paternalism occurs but not common feature of western } \\
\text { industrial medical regimes and should be frowned upon }\end{array}$ \\
\hline $\begin{array}{l}\text { Szasz \& Hollender, } \\
1956\end{array}$ & 1 & 0 & 1 & 1 & 3.0 & Informed consent is imperative to good medical practice \\
\hline $\begin{array}{l}\text { Sen (1992) and } \\
\text { Nussbaum (1993) }\end{array}$ & $1 / 2$ & 0 & 1 & 1 & 2.5 & Capacity is the sine qua non of autonomy \\
\hline O’Neill, (2002) & 0 & 0 & 1 & 1 & 2.0 & $\begin{array}{l}\text { EHIT affects trust which potentially could lead to } \\
\text { needless laboratory tests and treatment }\end{array}$ \\
\hline Tassano, (1995) & 0 & 0 & $1 / 2$ & 1 & 1.5 & $\begin{array}{l}\text { Exploitation of electronic health records for } \\
\text { evidence-based medicine }\end{array}$ \\
\hline Gillion, (1985) & 1 & 0 & 1 & 1 & 3.0 & $\begin{array}{l}\text { Individual liberty is as important as public } \\
\text { health and community's interests }\end{array}$ \\
\hline Edelstein (1943) & $1 / 2$ & 0 & $1 / 2$ & 1 & 2.0 & $\begin{array}{c}\text { Patients, irrespective of development in technology, } \\
\text { have a right to privacy }\end{array}$ \\
\hline $\begin{array}{l}\text { Freedman and } \\
\text { Weed, (2003) }\end{array}$ & 0 & 0 & $1 / 2$ & 1 & 1.5 & $\begin{array}{l}\text { Data mining should be improved to limit abuses } \\
\text { on autonomy and privacy }\end{array}$ \\
\hline $\begin{array}{l}\text { Gostin and } \\
\text { Hodge, (1999) }\end{array}$ & 1 & 0 & $1 / 2$ & 1 & 2.5 & $\begin{array}{l}\text { Data mining should be improved to limit abuses } \\
\text { on autonomy and privacy }\end{array}$ \\
\hline $\begin{array}{l}\text { Emmanuel and } \\
\text { Emmanuel, (1992) }\end{array}$ & 1 & 0 & $1 / 2$ & 1 & 2.5 & $\begin{array}{c}\text { Patient Electronic Health Records is not the property of } \\
\text { the physician or the hospital, hence autonomy with } \\
\text { participation of physician }\end{array}$ \\
\hline Vaah v. Lister, 2010 & 0 & 0 & $1 / 2$ & 1 & 2.5 & Patient autonomy extends to medical records \\
\hline $\begin{array}{l}\text { Emmet v. } \\
\text { Eastern, } 1967\end{array}$ & 0 & 0 & $1 / 2$ & 1 & 1.5 & Patients have right of access to their records \\
\hline Norman et al., 2010 & 0 & 0 & $1 / 2$ & 1 & 1.5 & Electronic records cannot erode patient’s confidentiality \\
\hline
\end{tabular}

in this section, none went as far as to advocate the need for indigenous cultures and society to develop their own ethical precepts rather than the wholesale adoption of the post World War 2 ethical precepts that emerged after the Nuremburg Trials.

\subsection{Paternalism and the Ethics of the Developing World}

Edwin (2008) commented that what prevails in the developing economies is the wholesale adoption of the medical ethics of the western industrialized world and its interpretive case law. The case law may be formulated also from the western point of view, and which may lie between the interface of medical ethics and law of the particular western nation. Edwin (2008) discussed the question of paternalism and teased out what pertains in clinical practice in Ghana in real time, although the discussion relied on conventional and western ethical precepts. The fact of the matter is that, the ethical standards of the western industrialized nations cannot be evaluated on the same ethical paradigm as, for example, those of Ghana or Nigeria. This is due to a myriad of reasons including 
the lack of standardization in medical training and local, regional and national practice (Sivalingam, 2011). This is why the advocacy in this paper proposes that a fresh look is taken at ethics from the lens of the respective nations of the sub-region.

\subsection{The Hierarchical Nature of National Culture and the Determination of Competence}

Sivalingam (2011) writing about the conflict between autonomy and competence as applied in the Malaysian medical situation wrote that at times the family's autonomy supersedes the patient's autonomy:

Societal approval of common law especially informed consent is again not clear especially when the family functions as a single unit and "family autonomy" is higher than the person's autonomy. Family units in some groups of society would want to play a pivotal role in decision making when risks of treatment involving their family member are explained.

The Malaysian situation is similar to what exists in many African nations and families, where family choice could override that of the individual irrespective of his capacity. Due to power dynamics within the marital home, often women appear to defer important personal medical decisions to their husbands. Another dimension to the difference between patients in Ghana compared to those in the UK, for example, is attributable to the hierarchical nature of the national culture. There is a great deal of demurring to elders, to the educated and the wise to make decisions that could affect the interests of the collective. In the sub-region, there is still veneration for the opinions of elders, the educated, the lawyer and the physician. Such esteem is carried into consulting rooms and offices of doctors by the patients. In the western industrialized nations, this function is performed by outside experts, professors that may indirectly influence the choices a patient makes with respect to a particular procedure for elective surgery, for example.

\subsection{Public Access to Health Information on Social Media and Television}

In terms of access to health information, whereas the average patient in the western industrialized nation has access to many sources of health and other information, the same cannot be said about a patient in Ghana or elsewhere in Sub-Sahara Africa. The average westerner gets health education directly and indirectly through television and syndicated shows like, "ER"; "Grey's Anatomy”; "Dr. Oz"; or the "Doctors”, the inhabitants of the developing world hardly receive health information except at the hospital or clinic. When there are television shows, they are often in the English language that naturally excludes millions of listeners who do not understand the language. Although it is easy to take for granted that television is in every home in nations like Ghana and Niger, the reality is quite shocking. For example, in 2002, Ghana ranked 143th with $26 \%$ penetration on the list of nations with television saturation in homes. Niger ranked 174th with only 5.4\% penetration of televisions to homes. About every ten people share one set of television, it is generally estimated (www.nationmaster.com, 2014). This does not mean to suggest that the patient in Ghana does not know and cannot tell his physician what ails him. What it really means is that the average patient in Ghana and elsewhere in Sub-Sahara Africa depends on his physician as the main source of medical information.

\subsection{Paternalism Is Complimentary to Autonomy}

The issue of paternalism in clinical practice appears to stand in stark opposite against autonomy. However, viewed from the lens of Ghana, or Sub-Sahara Africa, paternalism is complimentary to autonomy to the extent that it seeks to enrich and enhance individual capacity (Sivalingam, 2011). Due to the differences between the western ethical concept of paternalism for public health interventions and the Ghanaian approach for basic healthcare delivery, it appears none of the so-called "7 Rival Standards of Incompetence” articulated by researchers such as Beauchamp \& Childress (2001: p. 73) and others is descriptive or applicable in the Ghanaian context. Those standards provided by Beauchamp \& Childress are:

1) Inability to express or communicate a preference or choice;

2) Inability to understand one's situation and its consequences;

3) Inability to understand relevant information;

4) Inability to give a reason;

5) Inability to give a rational reason (although some supporting reasons may be given);

6) Inability to give risk/benefit-related reasons (although some rational supporting reasons may be given); 
7) Inability to reach a reasonable decision (as judged, for example, by a reasonable person standard).

The definition of capacity is again one of the major challenges with ethics in Sub-Sahara Africa. Sen (1992) defines capacity or capabilities in a linear progression: from commodity to function or functioning to utility or happiness. He also argued that wealth is not the only thing human beings want. They also want other things and therefore cannot use wealth as the denominator to determine the quality of life of a all people, since people have different goals and aspirations even within the same perhaps, homogenous society (Sen, 1992).

Since autonomy may be shared by the family and the individual, capacity too is a shared phenomenon that cannot be strictly enjoyed or expressed by the individual except when the person is 'alienated' from the family. In the African context, those that express individual capacity are those that are alienated from the family context, those that are self-actualized in a way akin to the western concept of autonomy. In fact, in the national consulting room, the patient expects the medical doctor to tell him what is wrong with him, despite his capacity to make decisions. Failure to do so by the doctor, at times would attract the vituperation of the patient or his surrogate. This is not for want of capacity but it is rather in consonance with the social expectation that elders, the educated professional such as a doctor probably knows best, compared to the average man in the matters of medicine.

Sen (1992) and Nussbaum (1993) defined capacity as a "person's ability to do valuable acts and reach valuable state of being". Whereas it is not difficult to accept that a person's sense of wellbeing is dictated by his capacity to do the things that are important to him, the attributes of capacity differs from one socio-political system to the other.

The following are examples of capabilities which the Ghanaian national considers as important which differ in many respects from the capability indicators of the western industrialized world (Sen, 1992; Nussbaum, 1993). These also define the functioning and capabilities within the context of the culture of the people of Ghana.

Examples of capabilities Ghanaians consider important

1) Ability to be in good social standing and acceptance;

2) Ability to enjoy religious freedom and worship;

3) Ability of others to think good thoughts and execute good deeds to benefit him;

4) Ability to award self-respect;

5) Ability to enjoy communal support for individual decisions;

6) Ability to experience communal decisions for individual action;

7) Ability to have good health and live long;

8) Ability to create, promote and maintain wealth;

9) Ability to display wisdom/leadership in complex social issues;

10) Ability to have personal and communal security;

11) Ability to marry and maintain a family;

12) Ability to have access to good housing with general amenities.

(Norman’s 12-point Ghanaian capability indicator, 2013).

In Ghana and in perhaps, many of the nations within Sub-Sahara Africa, paternalism of the physician in hospital and clinical work is common, even though this phenomenon is often not talked about openly. It is often glossed over as a minor irritant in the hollowed profession of medicine when the issue pops up in discourse and clinical audit (Ama Edwin, 2008).

\subsection{The Lack of Basic Education and Understanding of Medical Matters}

The statistics are daunting in terms of the real numbers of the people of Ghana who have no real functional education. For example, in the case of Ghana, those aged 15+ and who can read and write is only about $58 \%$ of the population of about 25 million, according to the 2010 Census. Literacy rate among males is $66.4 \%$ whiles among the females it is only about $49.8 \%$ also from the same source. In the 1990's the ratio of medical doctors to patients was 1:22,590. This may have improved marginally since the 1990's. Today, maternal death ratio is $350 / 100,000$ births whiles the national target was 180/100,000 births. About $57 \%$ of births are skill deliveries while over $40 \%$ are unskilled deliveries. The Ratio of Midwifes to population is 1:5300 in Ghana, with a shortfall of 5000 Midwifes (Ghana Statistical Service, 2010). When it comes to medical education, less than $2 \%$ of the national population can understand and appreciate effectively medical information concerning treatment, medication and disease etiology. This outcome exert enormous pressure on general civic education, public health and risk communication whether it is HIV/Aids, Ebola virus disease, cholera outbreak or household pro- 
tection against malaria and on health promotion.

Perhaps, the lack of basic education or the lack of basic understanding of medical matters has the same debilitating effect on autonomy as mental retardation. Just as it is said that prisoners and mentally challenged individuals have diminished capacity or autonomy, education or the lack of it can have the same incapacitating quality (Beauchamp \& Childress, 2001).

For the patient to express effective autonomy during his interface with the physician, the patient should come to the physician already formed in the image of the physician with the knowledge, skills and ability to discuss his medical situation and contribute about $50 \%$ input to his diagnosis and subsequent treatment. In addition to about $42 \%$ of the general population being educationally challenged, there are many inadequacies and vulnerabilities in terms of low income levels, the lack of savings, the lack of social networks and inclusion, which this segment of the population faces (Ghana Statistical Survey 2010). In such a dispossessed environment with stark differential vulnerabilities, physician paternalism is inevitable, informed-consent appears overrated and autonomy morphs as an ethical abstraction when it comes to dealing with the seemingly mythical but real $42 \%$ of the population being illiterate.

\subsection{Paternalism in Healthcare Delivery}

Emmanuel \& Emmanuel (1992) defined paternalism as the 'guardian of the patient' in their seminal paper on the models of physician-patient relationship. They noted that the physician as father or parent “... ensures that patients receive the treatment that is best for their health and well-being...” Buchanan defined paternalism (which he borrowed from Dworkin, 1988) in relation to public health intervention as:

“... interference with a person's liberty of action justified by reason referring exclusively to the welfare. of the person being coerced. Paternalism is the usurpation of decision making power, by preventing people from doing what they have decided, interfering in how they arrive at their decisions, or attempting to substitute one's judgment for theirs, expressly for the purpose of promoting their welfare. The moral concern is that the presumption that one is right, and therefore justified in seeking to override other people's judgment, constitutes treating them as less than moral equals. It denies people the right to choose their own ends of action, because it would not be necessary to supplant their decision if they shared the public health professionals' goals."

Obviously, the paternalism of the physician in clinical setting is frowned upon by medical ethics (Buchanan, 2008; Gostin, 2005; Emmanuel \& Emmanuel, 1992). The question is why? Why can't the health professional on whose technical advice (which could be nuanced, biased, full of or devoid of details), on which the patient ultimately relies; be paternalistic?

Sivalingam (2011) argued that, "it is ironical when a doctor has to decide on who gets care when resources become depleted and the general argument is that patient's self-determination must supersede doctor's autonomy”. Paternalism should not be confused with therapeutic privilege. Paternalism in its true demonstration of good will, good faith and honesty is complimentary to informed consent (Edwin, 2008).

\subsection{The Reality of Autonomy in Healthcare Delivery in the Developing World}

Autonomy is the ethical principle that the patient has the right of self-determination. Beauchamp \& Childress define personal autonomy to mean "self-rule that is free from both controlling that prevent meaningful choice" (Beauchamp \& Childress, 2001: p. 58).

They caution that:

Even autonomous persons with self-governing capacities sometimes fail to govern themselves in particular choices because of temporary constraints caused by illness or depression or because of ignorance, coercion or other condition that restrict their options.

Holland (2011) also echoes the same limitations in his book, Public Health Ethics on autonomy but borrows from Norman (2005: p. 72) to define autonomy thus:

One idea of the autonomous person seems to involve more than just the capacity to act on particular desires and choices. It suggests a more general capacity to be self-determining, to be in control of one's own life (Holland, 2011: p. 50).

The US Supreme Court's landmark public health ruling in 1905 in the case of Jacobson v. Massachusetts, 197 
US 11 (1905) shed light on the dilemma. The facts of the case were: Henning Jacobson, a minister and a Swedish immigrant to the US, lived in Cambridge, Massachusetts during an outbreak of smallpox in 1902. He refused to be vaccinated, because according to him, a vaccine had made him seriously ill as a child as well as other members of his own family. When he refused the vaccination, he was ordered to pay a fine of $\$ 5.00$, which he refused also to pay. The Massachusetts courts, including the Supreme Judicial Court rejected his arguments that compulsory inoculation violated the state and US constitutions. The US Supreme court ruled otherwise. In that case, the court found that:

“... the liberty secured by the US constitution to every person within its jurisdiction does not impart an absolute right in each person to be, at all times and in all circumstances, wholly freed from restraint. There are manifold restraints to which every person is necessarily subject for the common good..."

In a similar refrain, Mills (1977) articulated a more absolutist position although in actuality Mills' polemics on autonomy is subjected to many challenges. Even in jurisdictions where the right to die is honored legal traditions, one still needs to satisfy certain basic parameters:

The only part of the conduct of any one, for which he is amenable to society, is that which concerns others. In the part which merely concerns himself, his independence is, of right, absolute. Over himself, over his own body and mind, the individual is sovereign (Mill, 1975: p. 15).

Mill's position that although man is absolutely free and autonomous in all respect with regards to what he chooses to do to and with his body, that absolute right ends the moment its expression would clash with the interests of others was consistent with the Jacobson ruling. What the Jacobson ruling or Mills seemed to imply is the issue of ignorance as a counter-balance to autonomy.

For there to be a true and unimpeded exercise of autonomy, there has to be the absences of ignorance on the part of the patient and the availability of systematic information about a medical condition or disease to the patient. The absence of these renders the concept of autonomy inept in both clinical practice and public health ethics.

\subsection{Paternalism in the Face of Electronic Health Records}

There was a time the Physician-patient relationship used to be in a silo. Such a relationship was not opened to others except the physician and his retinue of assistants and technicians as well as co-workers within the hospital or clinical situation (Rothstein, 2010; Goodman, 2010). The advent of computers into the practice of medicine has helped to change the once formidable fortress and closed relationship to one that is almost ajar, which allows others to encroach on the personal health records of the patient without his or her prior consent (Bradt, 2009; Sinclair et al., 1999; Braddock, Fihn et al., 1997; Szasz and Hollender, 1956; Emmanuel and Emmanuel, 1992). The growth in the use of Electronic Health Records capture and management systems, perhaps, offers a strong support to paternalism today. The abuse of therapeutic privilege pre-Nuremburg cannot happen in a national universal health insurance scheme like that of Ghana. The stakeholders of the scheme include not only medical doctors but also accountants, auditors, policy makers and administrators and the personnel of allied health services that would not turn a blind eye if they witness or see therapeutic abuses by a medical doctor. It is therefore impossible in today's transparent world of modern medicine for a physician to carry out medical experimentation under the cover of therapeutic privilege.

Additionally, the duty of care placed on physicians to protect patient privacy is no longer the sole responsibility of the physician but a shared, communal responsibility spread among medical doctors, nurses, laboratory technicians, pharmacists, accounts specialists, insurance claims specialists, data processing clerks, and auditing firms. It is therefore unconscionable to expect only physicians to carry the burden of patient confidentiality. All confidential leaks are local and therefore a systems approach to the protection of confidentiality would be a more desirable approach. Consistent with the foregoing, other researchers believe that recording personal health history electronically, has already eroded that sacred relationship between the physician and the patient (Goodman, 2010). Therefore, to start now to erect protective walls around the patient and his history would not only disrupt the natural development of health informatics technology, but that it would arrest the developing transparency required in evidence-based research and public health, epidemiologic investigation, exposition and discourse. On the issue of autonomy, there are as many researchers who want to erect more impenetrable walls of protection on autonomy. There are also those who want it to be, at best, opened to medical and clinical research 
from a paternal, all knowing perspective of the physician without too much consultation with the patient (Beauchamp and Childress, 2001, Gostin \& Hodge, 1999, Emmanuel and Emmanuel, 1992). A corollary to the concept of self-determination is the expectation that the patient would self-inform, self-educate in all matters, medicine and all, as part of his health seeking behavior.

A patient is not necessarily being cheated out of his right to medical information if the doctor for whatever his or her reasons, elects not to share all of his or her professional thoughts with the patient after an evaluation. Ethical precepts of beneficence, Nonmaleficence, autonomy, etc should be viewed in the context of modern medicine (Norman, 2005; Peterson-Iyer, 2008). In the context of modern medicine, the doctor could argue that he found nothing, if compelled. Or the doctor is not the consultant of the patient? It may therefore be incongruent to the ethics of medical practice to demand that autonomy as an ethical value be in the mix of the essential ethical values to be observed by the healthcare provider and its personnel. Occasionally, the patient may consult the physician for advice and for explanation of his medical situation and challenges. The patient is not typically a medical doctor and even if he may be a medical doctor, he may not have the specialization in unique health challenges outside of his field of specialization. If the medical doctor is occasionally retained by the patient as a consultant to the patient, the patient is at liberty to take or reject the advice of the consultant. A consultant can only make recommendations to a particular situation based upon his training, specialization and abilities apropos his assessment of the risk involved. The patient therefore takes his consultant as he finds him.

\subsection{Paternalism and Medical Malpractice Suits}

Medical malpractice is based on the theory of negligence or battery. The lack of informed consent and encroachment on the autonomy of the patient could also be reasonable grounds for negligence particularly if a duty of care existed and which may have been breached. While there is a segment of the Ghanaian society that has become litigious, there is also the other segment that is hesitant to pursue malpractice law suits against healthcare professionals despite the occurrence of medical error or even morbidity or mortality. There are many reasons for this, significant among them are:-the average Ghanaian is superstitious and considers death, illness and misfortunes in general to be ignited and initiated by Satan and therefore does not see the point of blaming the medical doctor or nurse for his misfortune. They also believe that medicine is a pure, benevolent science. Its practitioners are infallible and very intelligent, people who work at near perfection with very little or no mistakes (Edwin, 2008). Therefore when a medical doctor makes a mistake, it is inevitable, an outcome pre-ordained by other forces beyond the mortal strength of the medical doctor. Patients are hesitant to audit and investigate the work of their physicians. Patients do not as a matter of routine ask their doctors about the length of a particular illness or procedure. The power dynamics of a doctor and his patient is akin to that of a dictatorial boss and his subordinate. The effect is that the medical doctor may engage in any activity he unilaterally sees okay, so long as it benefits the patient. Financially speaking, the average patient lacks capacity, let alone, has he the resources to see a second doctor for a second opinion. Due to this situation, the average patient may not have the financial resources to hire a lawyer to prosecute the potential case of medical malpractice, which is often costly and emotionally draining. This situation ends up with a great deal of unreported medical errors by doctors and nurses (Edwin, 2008).

\section{Conclusion and Recommendation}

The role of the physician in building the autonomy of the patient is underrated and needs to be revised. Informed-consent appears to be an ethical placebo which contributes very little to comprehension and appreciation of the patient's health status. It is also suggested that the average patient does not appreciate that the ethical requirement of Informed-Consent presumes a fiduciary relationship between the physician and patient. The average patient in the developing world is not able to fully understand and appreciate issues of autonomy, paternalism and informed-consent due to functional illiteracy in basic education or in medical matters. Autonomy or informed-consent correlates to the "right" to information which is modified by literacy in education and medicine. In this context the paternalism of the physician, although frowned upon by medical ethics, aims to promote the autonomy of the patient and thus his health-seeking behavior as well. The ability of the patient to give informed-consent is compromised to the extent of his education.

It is therefore being proffered here that the Ghana public and other stakeholders in the healthcare delivery system may accept the premise that medical doctors in Ghana simply do not have the time or energy to engage 
all patients in their clinical practice. They don't have the time and the resources to conduct extensive exploratory conversations about the patients' illness and options of treatment. Often times, doctors decide what is best for the patient after a brief clinical conservation with the patient or surrogate, due to the physician-patient ratio currently experienced by the nation. The public and the stakeholders could then develop a new set of medico-legal ethics for the protection of both the medical doctor and the patient in Ghana. They could also design modalities to address the nation's specific challenges but should not buy into the universal ethical standards for medical practice, which were designed for resource endowed climes and places.

\section{References}

Beauchamp, T. L., \& Childress, J. F. (2001). Principles of Biomedical Ethics (5 ${ }^{\text {th }}$ ed.). Oxford: Oxford University Press.

Braddock III, C. H., Edwards, K. A., Hasenberg, N. M., Laidley, T. L., \& Levinson, W. (1999). Informed Decision Making in Outpatient Practice: Time to Get Back to Basics. Journal of the American Medical Association, 282, 2313-2320. http://dx.doi.org/10.1001/jama.282.24.2313

Braddock, C. H., Fihn, S. D., Levinson, W., Jonsen, A. R., \& Pearlman, R. A. (1997). How Doctors and Patients Discuss Routine Clinical Decisions: Informed Decision-Making in the Outpatient Setting. Journal of General Internal Medicine, 12, 339-345.

Bradt, D. A. (2009). Evidence-Based Decision-Making in Humanitarian Assistance. Humanitarian Practice Network, Overseas Development Institute, 1-24.

Buchanan, D. R. (2008). Autonomy, Paternalism, and Justice: Ethical Priorities in Public Health. American Journal of Public Health, 98, 15-21. http://dx.doi.org/10.2105/AJPH.2007.110361

Castellano Marlene, B. (2004). Ethics of Aboriginal Research. Journal of Aboriginal Health, 1, 98-114.

Dworkin, G. (1988). The Theory and Practice of Autonomy. Cambridge: Cambridge University Press. http://dx.doi.org/10.1017/CBO9780511625206

Edelstein, L. (1943). The Hippocratic Oath: Text, Translation and Interpretation. 56.

Edwin, A. K. (2008). Don’t Lie but Don't Tell the Whole Truth: The Therapeutic Privilege-Is It Ever Justified? Ghana Medical Journal, 42, 156-161.

Edwin, A. K. (2009). Non-Disclosure of Medical Errors an Egregious Violation of Ethical Principles. GMJ, 43, 34-39.

Elizabeth Vaah v. Lister Hospital and Fertility Centre (2010). Suit \# HRCM 69/10.

Emmanuel, E. J., \& Emmanuel, L. I. (1992). Four Models of the Physician-Patient Relationship. Journal of the American Medical Association, 267, 2221-2226. http://dx.doi.org/10.1001/jama.1992.03480160079038

Emmet v. Eastern Dispensary and Casualty Hospital (1967). 130 U.S. App. D.C. 50, 396 F 2d 931.

Francis, L. P. (2010). The Physician-Patient Relationship and a National Health Information Network. Journal of Law, Medicine and Ethics, 38, 36-49.

Ghana Public Health Act (2012). Act 851. Government Printers, Barnes Avenue, Opp. Novotel Hotel, Accra, Ghana.

Ghana Statistical Service (2010). The Annual Statistical Survey. Ghana Statistical Service, Ministries, Accra, Ghana.

Gillion, R. (1985). Paternalism and Medical Ethics. British Medical Journal, 290, 1971-1972.

Goodman, K. W. (2010). Ethics, Information Technology, and Public Health: New Challenges for the Clinician-Patient Relationship. Journal of Law, Medicine and Ethics, 38, 58-63. http://dx.doi.org/10.1111/j.1748-720X.2010.00466.x

Gostin, L. O. (2005). Jacobson v Massachusetts at 100 Years: Police Powers and Civil Liberties in Tension. American Journal of Public Health, 95, 576-581. http://dx.doi.org/10.2105/AJPH.2004.055152

Gostin, L. O., \& Hodge, J. G. (1999). Model State Public Health Privacy Act (pp. 1-59). Washington DC: Georgetown University Law Center.

HIPAA (1996). U.S. Public Law (pp. 104-191).

Holland, S., \& Public Health Ethics (2010). Cambridge: Polity Press, 50.

Jacobson v. Massachusetts, 197 U. S. 11 (1905).

Mills, J. S. (1977). 15. On Liberty. Collected Works of John Stuart Mill (Vol. 18). Toronto: Toronto University Press.

Moulton, B., \& King, J. S. (2010). Aligning Ethics with Medical Decision-Making: The Quest for Informed Patient Choice. Journal of Law, Medicine and Ethics, 38, 85-97. http://dx.doi.org/10.1111/j.1748-720X.2010.00469.x

National Television Penetration Statistics. http://www.nationmaster.com.

Nigerian Orders Arrest of Pfizer Defendants. http://www.pharmalive.com 
Norman, I. D., Aikins, M., \& Binka, F. (2010). Ethics and Electronic Health Information Technology, Challenges for Evidence-Based Medicine and the Physician-Patient Relationship. Galen Medical Journal, 43, 115-125.

Norman, R. J. (2005) Autonomy in Applied Ethics. In T. Honderich (Ed.), The Oxford Companion to Philosophy (New Edition, p. 72). Oxford: Oxford University Press.

Nussbaum, M. C. (1993). Non-Relative Virtues: An Aristotelian Approach. In M. Nussbaum, \& A. Sen (Eds.), The Quality of Life. New York: Oxford Clarendon Press.

O’Neill, O. (2002). Autonomy and Trust in Bioethics (pp. 126-136). Cambridge: Cambridge University Press.

Peterson-Iyer, K. (2008). Pharmacogenomics, Ethics and Policy. 1-16, Markkula Center. http://www.scu.edu/ethics/publications/submitted/peterson-iyer

Rothstein, M. A. (2009). Improve Privacy by Eliminating Informed Consent? IOM Report Misses the Mark. Journal of Law, Medicine \& Ethics, 37, 507-509. http://dx.doi.org/10.1111/j.1748-720X.2009.00411.x

Rothstein, M. A. (2010). The Hippocratic Bargain and Health Information Technology. Journal of Law, Medicine and Ethics. 38, 7-13. http://dx.doi.org/10.1111/j.1748-720X.2010.00460.x

Sen, A. (1992) Capability and Well-Being. In M. Nussbaum, \& A. Sen (Eds.), The Quality of Life. New York: Oxford Clarendon Press.

Sivalingam, N. (2011). Medical Paternalism and Patient Autonomy; the Dualism Doctors Contend with. Medical Journal of Malaysia, 66, 421-422.

Szasz, T. S., \& Hollender, M. H. (1956). The Basic Models of the Doctor-Patient Relationship. Archives of Internal Medicine, 97, 585-592. http://dx.doi.org/10.1001/archinte.1956.00250230079008

Tassano, F. (1995). The Power of Life or Death: Medical Coercion and the Euthanasia Debate. Foreword by Szasz, T. MD. London: Duckworth; Oxford: Oxford Forum. 
Scientific Research Publishing (SCIRP) is one of the largest Open Access journal publishers. It is currently publishing more than 200 open access, online, peer-reviewed journals covering a wide range of academic disciplines. SCIRP serves the worldwide academic communities and contributes to the progress and application of science with its publication.

Other selected journals from SCIRP are listed as below. Submit your manuscript to us via either submit@scirp.org or Online Submission Portal.
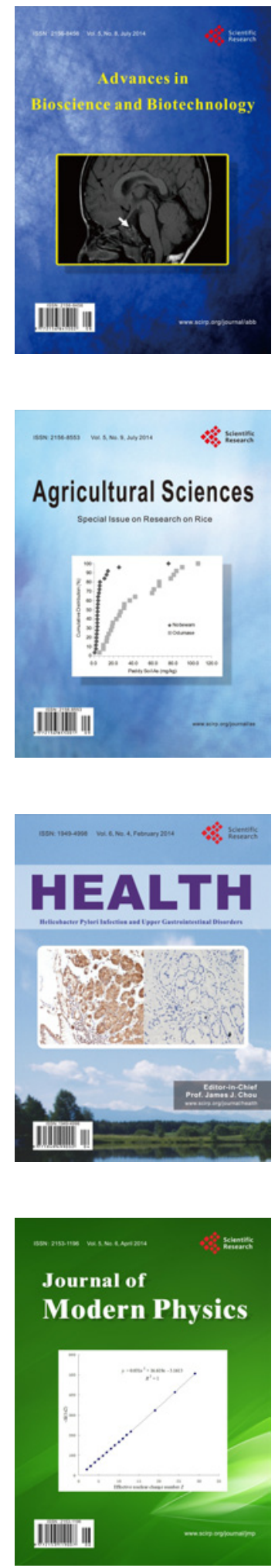
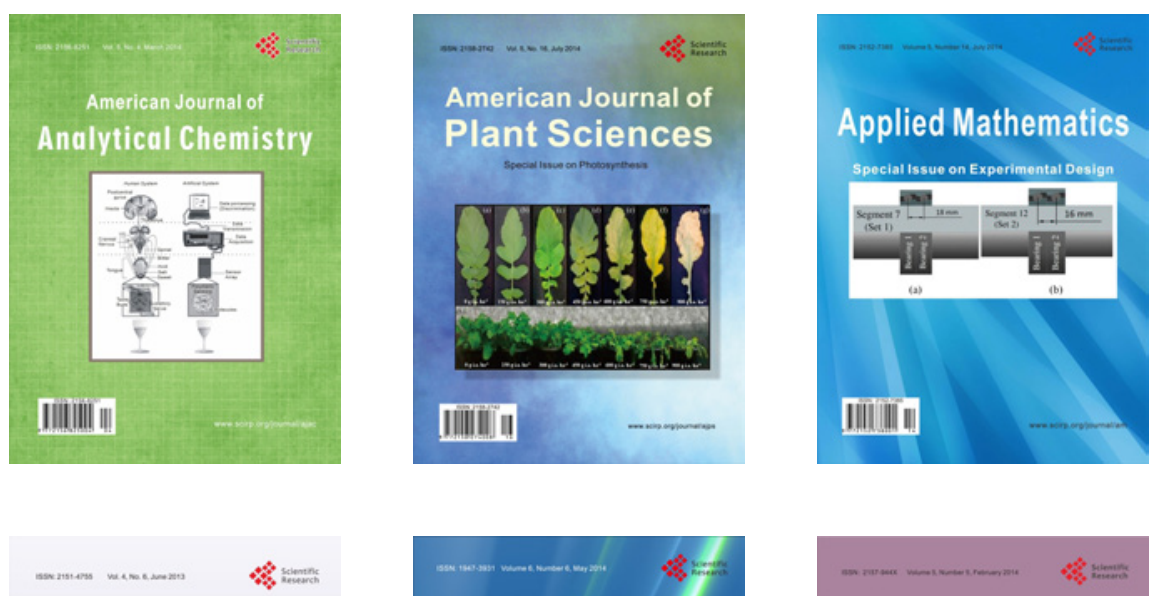

Creative Education
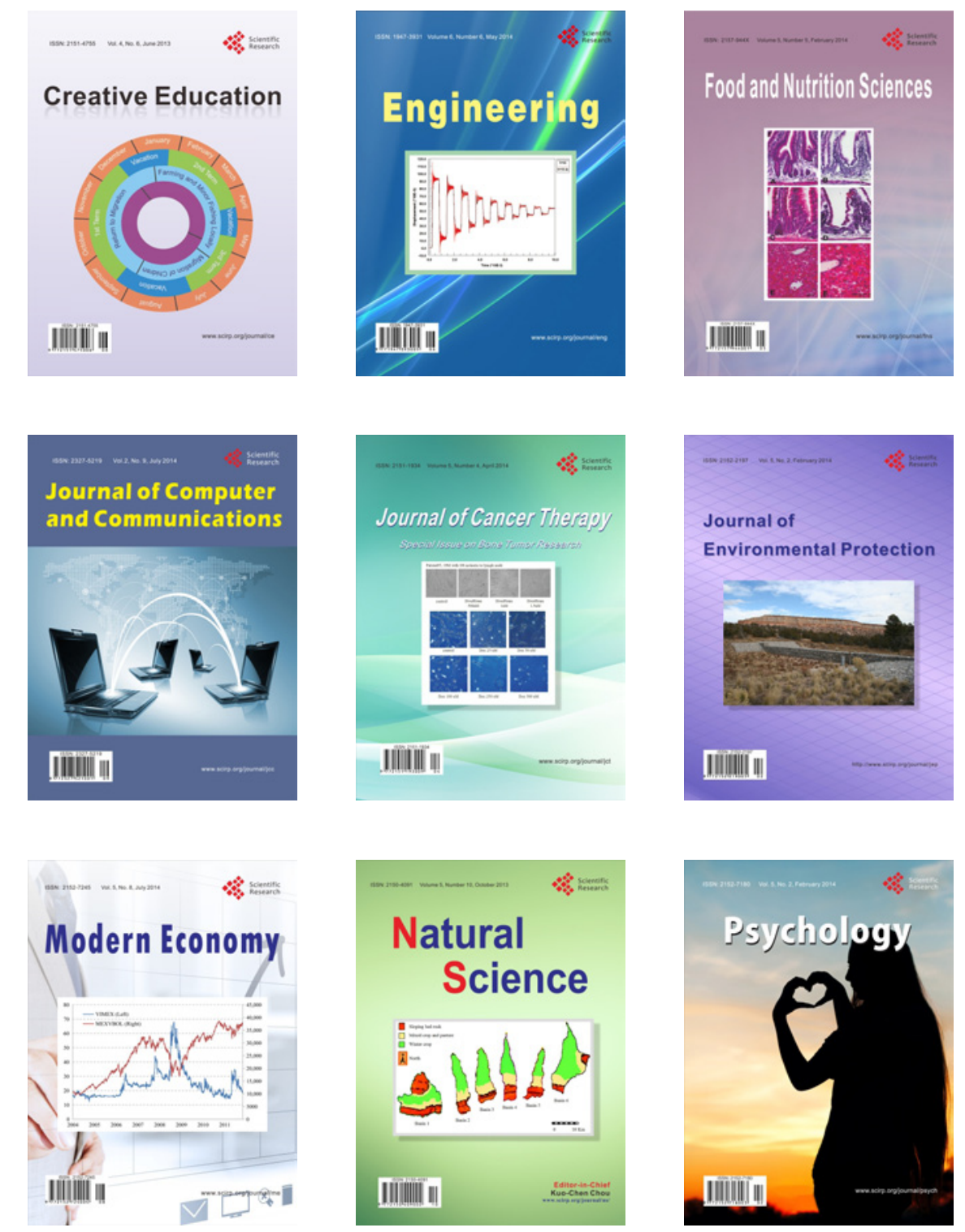